"Membaca karya Rumah Moderasi Beragama: Perspektif Lintas Keilmuan seperti dalam buku ini, memberikan spirit dan semangat berlebih dalam rangka penguatan berfikir dan bertindak moderat di kalangan PTKI (Perguruan Tinggi Keagamaan Islam). Karya-karya tulisan reflektif semacam ini juga dapat menjadi pendulum integrasi keilmuan di lingkungan PTKI, khususnya untuk menuju pendirian Universitas Islam Negeri. Selamat dan teruslah berkarya untuk terwujudnya keadilan sejak dalam pikiran"

$$
\sim \text { Dr. Mahrus, M. } A_{8}
$$

(Kepala Seksi Penelitian dan Pengelolaan Hak Kekayaan Intelektual Kemenag RI)

"Para Rektor PTKIN menelorkan buku dengan judul Moderasi Beragama dari Indonesia untuk Dunia (LKiS: 2019). Dengan tema yang sama, para dosen muda CPNS (angkatan 2018) IAIN Sultan Amai Gorontalo menulis, Rumah Moderasi Beragama: Perspektif Lintas Keilmuan. Kelebihan buku ini dibanding dengan buku sejenisnya, terletak pada gagasan yang ditawarkan, yakni; PTKIN menjadi Rumah Moderasi Beragama dan perspektif lintas keilmuan yang digunakan dalam memotret Moderas Beragama."

$$
\begin{aligned}
& \text { Beragama." } \\
& \sim \text { Dr. Sofyan AP Kau, M.Ag }
\end{aligned}
$$

Wakil Rektor 1/Bidang Akademik dan Pengembangan Lembaga IAIN Sultan Amai Gorontalo)

Buku Rumah Moderasi Beragama ini sebuah kumpulan teori dan aplikasi dengan pendekatan inter dan multi disiplin yang diahirkan oleh dosen-dosen muda, buku ini merupakan penghargaan keilmuan yang luar biasa, yang dapat menjadi rujukan dalam pengembangan keilmuan" $\sim$ Dr. Kasim Yahiji, M.Ag

$$
\begin{gathered}
\sim \text { Dr. Kasim Yahifi, M.Ag } \\
\text { (Direktur Pascasarjana IAIN Sultan Amai Gorontalo) }
\end{gathered}
$$

"Membaca adalah perintah Agama, dengan membaca dapat mempertahankan terjadinya regresi kehidupan, serdadu tak akan mati sepanjang masih membaca. Saat membaca buku karya dosen-dosen generasi milenial ini, membuat kita selalu merasa hidup, dan saat mengetahui cara pandang mereka terhadap Islam yang Moderat (Wasathiyah), saya dapat mempercayakan masa depan Pendidikan Islam dan PTKTN kepada generasi ini"
$\sim$ Dr. Lukman Arsyad, M.Pd

(Dekan Fakultas Tlmu Tarbiyah dan Keguruan IATN Sultan Amai Gorontalo)

"Pengembangan keilmuan dapat dilakukan oleh siapa saja, baik yang telah menggelutinya maupun yang akan memulainya. Gagasan yang merupakan hasil berpikir ilmiah telah diwujudkan oleh pemikir muda dengan menuangkan ide dan gagason Moderasi Beragama buku ini menjodi penting untuk libace, utamanya yang merind ukan elaborasi Mod

$$
\text { keilmuan yang lebih luas. }
$$

$$
\text { (Dekan Fakultas Syariah IAIN Sultan Amai Gorontalo) }
$$

"Buku ini merupakan kreasi dari intelektual-intelektual muda yang berkiprah di IAIN (segera bertransformasi ke UIN) Sultan Amai Gorontalo, dan sangat layak untuk dibaca dan mengisi referensi Moderasi Beragama di Indonesia bahkan Dunia"

$$
\sim \text { Dr. Mashadi, M.S }
$$

(Dekan Fakultas Ushuluddin IAIN Sultan Amai Gorontalo)

"Buku ini layak dijadikan sebagai referensi untuk membuka relung kekakuan berpikir kita dan kepicikan cara pandang terhadap Islam. Mari menyapa indahnya cakrawala dunia melalui Moderas Beragama."

$\sim$ Dr. Muhibbuddin, M.Si

(Dekan Fakultas Ekonomi dan Bisnis Islam IAIN Sultan Amai Gorontalo)

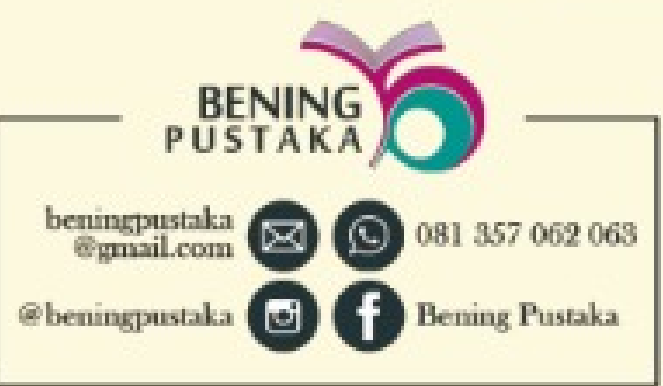

Kata Sambutan:

DR. Lahaji Haedar, M.Ag

()) (Rektor IAIN Sultan Amai

Gorontalo)

롤

Abdur Rahman Adi Saputra | Aminudin | Andiani Rezkita Nabu | Arfan Nusi Basri | Dian Adi Perdana | Dikson T. Yasin | Djunawir Syafar | Eka Apristian Pantu | Firman Sidik | Habibie Yusuf | M. Rifian Panigoro | Rifadli D. Kadir | Sitti Rahmawati Talango | Sri Aprianty Husain | Suheil sebagai Dukungan Terhadap Alih Status IAIN Menjadi UIN Sultan Amai Gorontalo) 


\section{RUMAH MODERASI BERAGAMA: PERSPEKTIF LINTAS KEILMUAN}

(Karya Tulis CPNS 2018 IAIN Sultan Amai Gorontalo sebagai Dukungan Terhadap Alih Status IAIN Menjadi UIN Sultan Amai Gorontalo) 
Sanksi Pelanggaran Pasal 113 Undang-undang Nomor 28 Tahun 2014 tentang Hak Cipta, sebagaimana yang diatur dan diubah dari Undang-undang Nomor 19 Tahun 2009, bahwa:

\section{Kutipan Pasal 113}

1. Setiap orang yang dengan tanpa hak melakukan pelanggaran hak ekonomi sebagaimana dimaksud dalam Pasal 9 ayat (1) Huruf i untuk Penggunaan Secara Komersial dipidana dengan pidana penjara paling lama 1 (satu) tahun dan/atau pidana denda paling banyak Rp. 100.000.000, 00 (seratus juta rupiah).

2. Setiap orang yang dengan tanpa hak dan/atau tanpa izin Pencipta atau pemegang Hak Cipta melakukan pelaggaran hak ekonomi Pencipta sebagaimana dimaksud dalam Pasal 9 ayat (1) huruf $c$, huruf $d$, huruf f, dan/atau huruf h untuk penggunaan Secara Komersial dipidana dengan pidana penjara paling lama 3 (tiga) tahun dan/atau pidana denda paling banyak Rp. 500.000.000,00 (lima ratus juta rupiah).

3. Setiap orang yang dengan tanpa hak dan/atau tanpa izin Pencipta atau pemegang Hak Cipta melakukan pelaggaran hak ekonomi Pencipta sebagaimana dimaksud dalam Pasal 9 ayat (1) huruf a, huruf b, huruf e, dan/atau huruf g untuk penggunaan Secara Komersial dipidana dengan pidana penjara paling lama 4 (empat) tahun dan/atau pidana denda paling banyak Rp. 1.000.000.000,00 (satu miliar rupiah).

4. Setiap orang yang memenuhi unsur sebagimana dimaksud pada ayat (3) yang dilakukan dalam bentuk pembajakan, dipidana dengan pidana penjara paling lama 10 (sepuluh) tahun dan/atau pidana denda paling banyak Rp. 4.000.000.000,00 (empat miliar rupiah). 
Kata Pengantar:

Prof. Dr. Oman Fathurrahman, M.Hum

(Staf Ahli Menteri Agama RI Bidang Manajemen Komunikasi dan Informasi)

Kata Sambutan:

DR. Lahaji Haedar, M.Ag

(Rektor IAIN Sultan Amai Gorontalo)

\section{RUMAH MODERASI BERAGAMA: PERSPEKTIF LINTAS KEILMUAN}

(Karya Tulis CPNS 2018 IAIN Sultan Amai Gorontalo sebagai Dukungan Terhadap Alih Status IAIN Menjadi UIN Sultan Amai

Gorontalo)

Penulis:

Abdur Rahman Adi Saputra || Aminudin || Andiani Rezkita Nabu || Arfan Nusi || Basri || Dian Adi Perdana || Dikson T. Yasin || Djunawir Syafar || Eka Apristian Pantu || Firman Sidik || Habibie Yusuf || M. Rifian Panigoro || Rifadli D. Kadir || Sitti Rahmawati Talango || Sri Aprianty Husain || Suheil

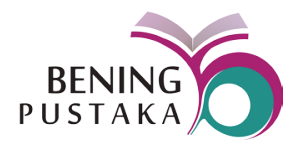

Yogyakarta, 2019 
RUMAH MODERASI BERAGAMA:

PERSPEKTIF LINTAS KEILMUAN

(C) 2019, Abdur Rahman Adi Saputra || Aminudin || Andiani Rezkita Nabu || Arfan Nusi || Basri || Dian Adi Perdana || Dikson T. Yasin || Djunawir Syafar || Eka Apristian Pantu || Firman Sidik || Habibie Yusuf || M. Rifian Panigoro || Rifadli D. Kadir || Sitti Rahmawati Talango || Sri Aprianty Husain || Suheil

Tata letak dan desain oleh Gavin

Desain sampul oleh Fajar

Penyunting oleh Dr. Ahmad Faisal, M.Ag., Khaeroni, M.Si., Habibie Yusuf, S.Pd.I, M.Pd.

Diterbitkan oleh

Bening Pustaka

Jalan Santan No. 35A Maguwoharjo, Yogyakarta

081357062063

beningpustaka@gmail.com

www.booqoe.com

Cetakan pertama, November 2019

Hak cipta dilindungi oleh undang-undang.

Dilarang memperbanyak sebagian atau seluruh buku ini dalam bentuk apa pun tanpa izin dari Penerbit.

xii+ 188 hlm.; $14 \mathrm{~cm}$ x $21 \mathrm{~cm}$

ISBN. 978-623-7104-xx-x 


\section{KATA PENGANTAR \\ (Staf Ahli Menteri Agama RI Bidang Manajemen Komunikasi dan Informasi)}

Saya sangat menyambut baik penerbitan buku Rumah Moderasi Beragama: Perspektif Lintas Keilmuan, yang berisi kumpulan tulisan para penulis muda kalangan Calon Pegawai Negeri Sipil (CPNS) Institut Agama Islam Negeri (IAIN) Sultan Amai Gorontalo ini. Meski kualitas dan substansi tulisan masih dapat dipertajam dan disempurnakan, namun ini adalah preseden yang baik bahwa sejak awal para calon abdi negara tersebut telah membiasakan menuliskan gagasan dan pemikirannya, khususnya terkait dengan moderasi beragama, sesuai dengan perspektif dan bidang keilmuan yang digeluti.

Moderasi beragama adalah satu nomenklatur gagasan yang dikemukakan oleh Menteri Agama Periode 1 Kepemimpinan Presiden Bapak Jokowi, yakni Bapak Lukman Hakim Saifuddin. Ia telah mulai menggaungkan moderasi beragama sejak awal kepemimpinannya di Kementerian Agama. Moderasi beragama ditafsirkan sebagai cara pandang, sikap, dan perilaku selalu mengambil posisi di tengah-tengah, selalu bertindak adil, dan tidak ekstrem dalam beragama. Orang yang mempraktikkan moderasi beragama biasa disebut sebagai seorang yang moderat.

Di kalangan masyarakat Muslim khususnya, label "moderat" sering disalah paham sebagai "liberal", tidak teguh dalam beragama, atau tidak kaaffah. Ini tentu harus diluruskan, karena moderasi beragama sesungguhnya adalah istilah lain dari wasathiyah (jalan tengah), yang nilai-nilainya, yaitu adil (i'tidal) dan seimbang (tawazun), sesungguhnya merupakan bagian dari ajaran esensial dalam Islam.

Karenanya, menjadi seorang yang moderat berarti juga harus memiliki pendirian teguh dan semangat beragama yang tinggi. 
Namun, ia harus mampu memilah mana pokok ajaran agama, di mana ia harus berpendirian teguh, dan mana tafsir ajaran agama, di mana ia perlu toleran, menghormati pendirian orang lain, dan tidak menyalah-nyalahkan, apalagi mengkafir-kafirkan. Terkait urusan pokok agama, tidak boleh ada kompromi dalam hal meyakini dan mempraktikkannya. Tapi untuk urusan agama yang sifat hukumnya diperdebatkan, dan ada beragam pandangan, seorang moderat akan mengambil sikap hukum tertentu untuk dirinya, tapi tidak memaksakan hukum itu berlaku untuk orang lain. Itulah makna toleran.

Bapak Lukman Hakim Saifuddin, mengemukakan gagasan moderasi beragama ini terkait dengan kenyataan bahwa dalam kehidupan umat beragama di Indonesia, keragaman adalah hal yang niscaya, baik keragaman agama, maupun keragaman budaya, bahasa, etnis ,dan lainnya. Keragaman ini seringkali mengakibatkan sikap berlebih-lebihan atau ekstrem dari masing-masing pihak untuk mempertahankan kebenaran tafsir agamanya, sehingga menimbulkan konflik.

Saya berharap tulisan-tulisan para akademisi muda di buku ini menjadi awal terhadap tulisan-tulisan lainnya terkait dengan moderasi beragama, yang masih harus terus diproduksi dengan berbasis riset yang lebih baik. Civitas akademika PTKIN, semacam UIN, IAIN, dan STAIN, yang memiliki basis dan akar kuat keilmuan Islam harus menjadi lokomotif terdepan dalam menebarkan pesan-pesan agama yang penuh dengan kedamaian, toleransi, sesuai dengan misi rabmatanlil 'alamin. 


\section{KATA SAMBUTAN (Rektor IAIn Sultan Amaj Gorontalo)}

Puji syukur ke hadirat Allah SW'T, dan menyambut dengan rasa syukur atas penerbitan buku ini, yang merupakan kolaborasi dari Dosen Muda IAIN Sultan Amai Gorontalo (CPNS angkatan 2018), sebagai bagian dari peningkatan tradisi keilmuan di perguruan tinggi.

Tema Rumah Moderasi Beragama: Perspektif Lintas Keilmuan, merupakan titik pijak dari diskusi buku ini,dengan mempertimbangkan pentingnya gagasan moderasi beragama di tengah-tengah berbagai serbuan paham, maupun gerakan sosialkeagamaan yang terus menguji nilai-nilai ke-Indonesiaan kita sebagai masyarakat yang majemuk.

Berbagai gagasan dalam buku ini, dimaksudkan menjadi bagian dari bentuk perenungan dan diskusi bersama, bagaimana keberadaan perguruan tinggi Islam (STAIN, IAIN, UIN, dan lain sebagainya) hadir di tengah-tengah berbagai persoalan sosialkeagamaan yang tidak akan pernah ada habisnya. Itulah sebabnya, gagasan moderasi beragama diharapkan menjadi sebuah model, rujukan, bahkan metodologi yang perlu untuk terus menerus dikembangkan, agar menjadi wawasan bagi seluruh warga kampus, serta ikut berdampak sampai ke masyarakat. Prinsip-prinsip moderasi beragama di Indonesia, kata kuncinya sebetulnya sudah dipertegas oleh nilai-nilai dalam Pancasila sebagai dasar Negara Indonesia.

Ke depannya, kita perlu untuk terus melanjutkan upaya menulis bersama atau kolaborasi akademik dengan berbagai pihak dan lembaga mana pun, agar menghasilkan tema-tema yang lebih beragam dan menarik, sehingga fungsi Perguruan Tinggi Islam sebagai pusat pengkajian Islam dan ilmu pengetahuan dapat terwujud. Ucapan terimakasih banyak kepada Dosen-Dosen 
Muda IAIN Sultan Amai Gorontalo (CPNS angkatan 2018) yang telah mempersembahkan karya ini. Selamat membaca!!

Gorontalo, 05 Oktober 2019 


\section{Daftar Isi}

KATA PENGANTAR

(Staf Ahli Menteri Agama RI Bidang Manajemen Komunikasi dan Informasi)

$\mathrm{V}$

KATA SAMBUTAN

Vii

(Rektor IAIN Sultan Amai Gorontalo)

Multilingualism in Constructing Indonesian Islamic Moderation -A Linguistic Perspective

By: Andiani Rezkita Nabu, S.Pd, M.A 1

References

علم العقبدة على منهج الثيخ عبد الله الهرري

بطريقة التحذير الثر عي الثي

10

WASATHIYAH DALAM AL-QUR'AN

(Memahami Eksistensi Islam sebagai "Ummatan Wasathan"

dalam Surah al -Baqarah ayat 143)

Oleh: Basri, M.Hum

REFERENSI

GAGASAN ZAKAT ONLINE SEBAGAI POTRET

MODERNISASI DAN MODERASI UMAT

Oleh: Dian Adi Perdana, M.M

REFERENSI

EKSISTENSI DAN BAHAYA PEREMPUAN DI RUANG

PUBLIK (Kritik Atas Pemahaman Hadits Khaled Abou El Fadl tentang fitnah Perempuan)

Oleh: H. Rifian Panigoro, M.A

REFERENSI 
Islamic Montessori: Metode Moderasi dalam Pendidikan Anak

Oleh: Sitti Rahmawati Talango, M.Pd

Penghulu dan Moderasi Beragama Pasangan Keluarga Muslim

Oleh: Dikson T. Yasin, M.HI

Teman Baru di Sekolah Baru dalam Perspektif Islam dan

Psikologi

Oleh: Eka Apristian Pantu, S.Psi., M.Si 86

Referensi

Manusia Di Antara Cinta Dan Kebencian:Transformasi NilaiNilai Islam Rahmatan Lil'alamin

Oleh: Arfan Nusi, M.Hum

Pembaruan Pendidikan Islam dan Visi Kemanusiaan

Oleh: Firman Sidik, M.Pd.I

REFERENSI

Aktualisasi Social Control Sebagai Upaya Moderasi Hukum Islam di Indonesia

Oleh: Abd. Rahman Adi Saputera Budiono, M.H.I.

Bank Syariah Dalam Pusara[n] Moral

Oleh: Sri Apriyanti Husain, M.S.A

Ketuhanan dalam Pancasila, Kekerasan atas Nama Agama, dan Peran Lembaga Pendidikan

Oleh: Djunawir Syafar, M.Pd 
Memperbincangkan Etika Sufistik-Filosofis Dalam Pandangan Al-Ghazali dan Implikasinya Terhadap Nilai-Nilai Islam

Ramah

Oleh: Aminudin, S.Fil.I.,M.Hum

Moderasi Islam dalam Pembangunan Ekonomi: dari Sejahtera ke Bahagia

Oleh: Rifadli D. Kadir, M.E.K 162

Referensi 168

Dinamika Ahli Status PTKIN Era Industri 4.0 dan Rumah

Moderasi Beragama

Oleh: Habibie Yusuf, S.Pd.I, M.Pd 170

REFERENSI 182

$\begin{array}{ll}\text { TENTANG PENULIS } & 184\end{array}$ 


\section{Dinamika Ahli Status PTKIn Era Industri 4.0 dan Rumah Moderasi Beragama}

Oleb: Habibie Yusuf, S.Pd.I, M.Pd

\section{Alih Status PTKIN (Perguruan Tinggi Keagamaan Islam Negeri)}

Perguruan Tinggi Keagamaan Islam (PTKI) di Indonesia baik yang dikelola oleh negara (baca: PTKIN) maupun yang dikelola pihak swasta (baca: PTKIS) pada realitasnya sedang dihadapkan pada persoalan mendasar. Persoalan tersebut - pada satu sisiterkait dengan out put-nya yang disinyalir belum terakomodasi secara lebih aktif ke dalam berbagai tuntutan dan kebutuhan di tengah persaingan yang demikian hebat. Pada sisi lainnya tuntutan perubahan terus menggelinding seiring dengan dinamika yang berkembang. Problem tersebut bukan hanya terjadi pada PTKI di Indonesia, namun juga telah terjadi hampir di sebagian besar Perguruan Tinggi keagamaan Islam di belahan dunia.

Hasil kajian yang pernah dilakukan Bassam Tibi menginformasikan, hampir seluruh perguruan tinggi Islam yang berada di kawasan Timur Tengah dan Afrika sangat menekankan kapasitas untuk menghapal agar mahasiswa bisa lulus dalam studi mereka; tidak pada kapasitas untuk berfikir kritis dan analitis. Dalam konteks ini, mahasiswa dipersiapkan bukan dalam rangka menghadapi tantangan zaman yang terus berubah, akan tetapi lebih kepada stabilisasi dan gengsi. Konsekuensinya adalah, setelah mereka lulus dari studi, yang didapatkan oleh mahasiswa hanyalah selembar ijazah, tidak pada kualifikasi yang dapat dijadikan bahan sebagai bekal dalam menghadapi perubahan yang sedemikian dahsyatnya. Gelar akademis dianggap lebih penting dan memiliki nilai prestise di banding dengan bidang keahlian dan kualifikasinya. ${ }^{250}$ Kesimpulan Bassam Tibi tersebut kiranya sangat

250 Lihat Bassam Tibi, Islam and the Cultural Accommodation of Social Change, (Boulder: 1991), h. 110. 
bersinggungan dengan kondisi Perguruan Tinggi Islam (PTKI) di Indonesia. Azyumardi Azra pernah juga memberikan laporan, bahwa mahasiswa di Indonesia belajar ke Perguruan Tinggi pertama-tama adalah untuk mengejar status dan selembar ijazah, bukan keahlian, keterampilan dan profesionalisme. ${ }^{251}$ Jika yang dikejar (hanya) selembar ijazah, perlu juga diingat apa yang sering disampaikan Rocky Gerung: "Ijazah itu hanya sebagai tanda anda pernah sekolah, tanda anda pernah belajar adalah membaca".

Fenomena perubahan kelembagaan Perguruan Tinggi Keagamaan Islam Negeri (PTKIN) dan Perguruan Tinggi Keagamaan Islam Swasta (PTKIS) pada dekade mutakhir ini telah menunjukkan perkembangan luar biasa seiring dengan dinamika yang berkembang. Perubahan institusional tersebut tentunya sebagai salah satu ikhtiyar untuk menjadikan PTKI tetap survive di tengah terpaan problem perubahan yang terus bergerak. Perubahan tersebut misalnya yang dikelola oleh Negara: Dari STAIN ke IAIN dan dari IAIN ke UIN. Juga yang dikelola oleh swasta: Dari STI ke STAI, dari STAI ke IAI, dan dari IAI ke UI. Memang perubahan tersebut seakan tidak dapat dihindari dengan mempertimbangkan aspek perkembangan zaman, kemajuan ilmu pengetahuan dan teknologi, serta tuntutan masyarakat yang terus berubah.

Seiring dengan perubahan tersebut, sebenarnya tidak sedikit problem yang mengiringinya, antara lain: Apakah PTKI telah siap secara teknis dan akademis dalam melakukan akselarasi di tengah perubahan ini? Bagaimana strategi dalam menyongsong perubahan yang sedemikian hebat di tengah persaingan global? Bagaimana di satu sisi nilai-nilai keagamaan tetap menjadi ruh dalam pendidikan, sementara pada sisi lainnya PTKI harus dapat sejalan dengan tingkat kebutuhan masyarakat yang terus berubah? Bagaimana tingkat jaminan mutu pendidikan agar dapat terus mengalami peningkatan? Bagaimana daya saing dengan Perguruan

251 Azyumardi Azra, "Pendidikan Tinggi Islam dan Kemajuan Sains (Sebuah Pengantar)", dalam Charles Michael Stanton, Pendidikan Tinggi dalam Islam, Terj. H. Afandi dan Hasan Asari, (Jakarta: Logos, 1994), h. xv. 
Tinggi lainnya, baik dalam konteks Indonesia maupun dalam konteks global (dunia)?, dan masih seabrek persoalan yang muncul seiring perubahan-perubahan yang dihadapi oleh PTKI saat ini.

Pendidikan tinggi yang berada di bawah pembinaan Kementerian Agama terdiri dari Sekolah Tinggi Agama Islam, Institut Agama Islam, dan Universitas Islam. Dalam nomenklatur yang berlaku di Kementerian Agama disebut dengan Pendidikan Tinggi Keagamaan Islam (PTKI). Sesuai dengan fenomena kelembagaan pendidikan tinggi keagamaan Islam terkini, sejak tahun 2014 khususnya, bahwa ada beberapa PTKIN yang berubah statusnya dari Sekolah Tinggi menjadi Institut dan dari Institut menjadi Universitas. Saat ini (04 November 2019) Jumlah PTKIN total ada 58 PTKIN yang terdiri dari 17 UIN (Universitas Islam Negeri), 34 IAIN (Institut Agama Islam Negeri), dan 7 STAIN (Sekolah Tinggi Agama Islam Negeri). Banyak alih status yang terjadi pada PTKIN di jaman Bapak Lukman Hakim Saifuddin (LHS)/Menteri Agama Periode 1 Kepemimpinan Bapak Jokowi, beliau juga-lah di Kementerian Agama yang mengarus-utamakan kembali pending Moderasi Beragama.

Berdasarkan Peraturan Menteri Agama Republik Indonesia Nomor 15 Tahun 2014 Tentang Perubahan Bentuk Perguruan Tinggi Keagamaan Bab I Ketentuan Umum, pasal 1 ayat (1) Perguruan Tinggi Keagamaan yang selanjutnya disingkat PTK adalah perguruan tinggi keagamaan yang didirikan dan/atau diselenggarakan oleh pemerintah dan/atau masyarakat di bawah pembinaan Kementerian Agama. (2) Universitas adalah perguruan tinggi keagamaan yang menyelenggarakan pendidikan akademik, pendidikan vokasi, dan/atau pendidikan profesi dalam sejumlah ilmu pengetahuan, teknologi dan/atau seni. (3) Institut adalah perguruan tinggi keagamaan yang menyelenggarakan pendidikan akademik, pendidikan vokasi, dan/atau pendidikan profesi dalam sekelompok disiplin ilmu pengetahuan, teknologi, dan/atau seni. (4) Sekolah Tinggi adalah perguruan tinggi keagamaan yang menyelenggarakan pendidikan akademik, pendidikan vokasi, dan/ 
atau pendidikan profesi dalam lingkup satu disiplin ilmu tertentu.

Di dalam PMA 15 tahun 2014 pasal 3 Perubahan bentuk PTK dilakukan atas dasar kebutuhan masyarakat, pengembangan ilmu pengetahuan, teknologi, dan/atau seni, kebutuhan pembangunan nasional, dan pertumbuhan jumlah mahasiswa. Adapun tujuannya adalah meningkatkan akses pendidikan tinggi keagamaan, meningkatkan daya jangkau pemerataan dan sebaran pendidikan tinggi keagamaan, dan meningkatkan mutu dan daya saing penyelenggaraan pendidikan tinggi keagamaan. ${ }^{252}$

\section{Rumah Moderasi Beragama Dan Era Industri 4.0}

Berbicara revolusi industri 4.0 (teknologi internet) dan kaitannya dengan pendidikan tentu saja dunia pendidikan adalah hal yang utama dan sentral untuk mengikuti arus revolusi industri ini karena akan mencetak dan menghasilkan generasi-generasi berkualitas yang akan mengisi revolusi industri 4.0. Pendidikan di era revolusi industri 4.0 berupa perubahan dari cara belajar, pola berpikir serta cara bertindak para peserta didik dalam mengembangkan inovasi kreatif berbagai bidang.

Dengan hal ini, dapat menekan angka pengangguran di Indonesia khususnya dalam persaingan pasar global, Revolusi industri generasi empat tidak hanya menyediakan peluang, tetapi juga tantangan bagi generasi milineal. Kemajuan ilmu pengetahuan dan teknologi sebagai pemicu revolusi industri, juga diikuti dengan implikasi lain seperti kompetisi manusia vs mesin, dan tuntutan kompetensi yang semakin tinggi. ${ }^{253}$

Untuk itu inovasi teknologi di bidang pendidikan untuk mendukung pembelajaran sangat dibutuhkan pada era ini untuk meningkatkan kualitas sumber daya manusia supaya bisa bersaing di kancah global, maka diperlukan lembaga-lembaga pendidikan dan guru-guru untuk melakukan pembelajaran kreatif dan inovatif. Tentunya ini akan berjalan apabila didukung dengan teknologi

252 Disebutkan pada pasal 2 PMA 15 tahun 2014

253 Castetter, William. B. (1996). The Human Research for Educational Administration. New Jersey : A. Simon \& Schus t e r Company. 
informasi dan komunikasi di era revolusi industri 4.0.

Selain sebagai agama yang menduduki posisi mayoritas di tengah keberagaman agama-agama di Indonesia, Islam di negeri kepulauan ini, dikenal sebagai agama yang menjunjung tinggi nilainilai toleransi dan keluhuran adab yang adi luhung. Persenyawaan yang harmonis antara ajaran substansial agama Islam dengan kebudayaan nusantara, menjadikan agama ini menempati posisi tersendiri di hati masyarakat. Namun sayangnya, realitas ini berlaku di era pra reformasi ke belakang. Pasca runtuhnya era orde baru tahun 1998 silam sampai saat ini, wajah Islam di Indonesia cenderung ditampilkan dengan semakin garang dan geram.

Kenyataan ini, diperburuk dengan semakin canggihnya teknologi informasi, sehingga turut serta dalam membentuk opini di masyarakat, khususnya antar pemeluk agama Islam, dan umumnya antar agama. Sehingga, saat ini tidak sulit menemukan sesama umat islam saling berbenturan dan berhadap-hadapan karena perbedaan penerimaan informasi dari media online.

Kini, fenomena saling hujat dan laknat seakan menjadi menu keseharian umat Islam Indonesia, maupun antar umat Beragama, nyaris tiada hari tanpa caci maki. Hal ini tentu jika dibiarkan, akan berdampak pada lunturnya semangat moderasi yang selama ini menjadi keunggulan sifat yang dimiliki Islam di Nusantara. Maka, menjadi sangat relevan jika semangat moderasi (washatiyah) kembali digaungkan di tengah generasi millennial yang sebagian besar hidupnya terkuras habis di dunia digital.

Revolusi Industri 4.0 bukanlah ancaman bagi agama, pun sebaliknya agama bukanlah ancaman terhadap revolusi Industri 4.0. Dalam kaitan ini perlu ditekankan pentingnya usaha mengharmoniskan ilmu pengetahuan dan teknologi (Iptek) dengan agama (Imtaq). Iptek harus selalu dilandasi oleh nilai-nilai moral-agama agar tidak bersifat destruktif terhadap nilai-nilai kemanusiaan (dehumanisasi). Sedangkan ajaran dalam beragama harus didekatkan dengan konteks modernitas, sehingga dapat bersifat kompatibel dengan segala waktu dan tempat. 
Hal ini merupakan keniscayaan yang mesti harus dihadapi oleh umat beragama karena revolusi industri 4.0 yang mesti harus dipahami bagi kita semua adalah munculnya inovasi disruptif (disruptive innovation) adalah inovasi yang memunculkan kondisi baru yang kadang tidak banyak yang bisa menduga, mengganggu atau merusak kondisi yang sudah ada.

Istilah disruption mulai ramai dibicarakan di Indonesia sejak Rhenald Kasali mempopulerkannya melalui buku yang berjudul Disruption: Tak Ada yang Tak Bisa Diubah Sebelum Dihadapi, Motivasi Saja Tidak Cukup. Sebagai sebuah tahapan sejarah, disruption menurut Kasali ditandai dengan empat indikator, yaitu simpler (lebih mudah), cheaper (lebih murah), accesible (lebih terjangkau), dan faster (lebih cepat). ${ }^{254}$

Keempat indikator inilah yang paling dicari dan diminati oleh generasi saat ini. Jika terdapat sesuatu yang dapat diperoleh dengan mudah, murah, cepat dan bisa di jangkau, maka sesuatu tersebut pasti menjadi pilihan yang tak bisa dihindarkan. Salah satu penyokong utama era disruption ini adalah generasi milenial. Hal ini dikarenakan generasi inilah yang paling aktif dalam merespon gempuran teknologi informasi yang meningkat begitu pesat. Dan, pada faktanya, maraknya situs dakwah, baik berupa youtube, website bertajuk portal islam, akun media sosial dan lain sebagainya, menjadi pilihan alternative di saat masyarakat sibuk dengan pekerjaan masing-masing. Realitas ini seakan menjadikan akses internet sebagai jalan tol dalam memperdalam "pemahaman agama". Pada posisi inilah era disruptif menancapkan taringnya dalam ajaran islam.

Jika di kontekstualisasikan dengan ajaran-ajaran Islam, maka saat ini menjadikan internet sebagai sumber pembelajaran utama dalam memperdalam ilmu agama menjadi hal yang tak bisa terelakkan. Dan pada faktanya, dewasa ini banyak pendakwah yang menjadikan internet sebagai media dakwahnya.

254 Rhenald Kasali, Disruption: Tak Ada yang Tak Bisa Diubah Sebelum Dihadapi, Motivasi Saja Tidak Cukup (Jakarta: Gramedia Pustaka Utama, 2017), h. 17. 
Di sisi lain, belakangan ini lembaga Pendidikan Islam harus mulai menaruh perhatian terhadap generasi millennial, dan generasi Z. Lembaga Pendidikan Islam yang masih mendefinisikan urusan manusianya dengan konsep human resource (HR) akan kewalahan menghadapi generasi millennial dan generasi $\mathrm{Z}$. Sebaliknya, lembaga Pendidikan Islam yang memperhatikan ledakan (Bonus Demografi) generasi milenial dan generasi $\mathrm{Z}$ ini sebagai human capital, akan banyak memperoleh pengaruh dan berpotensi dijadikan sebagai aset dan penentu masa depan. Maka untuk mengadapi Industri 4.0 pada Bonus Demografi (ledakan usia produktif yang diwakili dengan generasi Milenial dan generasi Z) penulis menganalisis konsep Rumah Moderasi Beragama untuk seluruh PTKIN menjadi solusinya.

\section{Rumus Ahli Status PTKIN}

Perubahan PTKIN dari STAIN ke IAIN dan dari IAIN ke UIN harus dipahami sebagai suatu langkah progressif perihal transformasi kelembagaan (yang berpengaruh kepada hal-hal akademis lainnya) menuju PTKIN yang lebih baik, sehingga tetap survive di tengah geliat Industri 4.0 pada Bonus Demografi (ledakan usia produktif yang diwakili dengan generasi Milenial dan generasi Z) yang semakin tak terbendung saat ini. PTKIN harus dapat menyesuaikan diri dengan perkembangan-perkembangan yang terjadi yang demikian cepatnya, dengan tetap berlandaskan pada Moderasi Beragama atau bahkan menjadikan PTKIN menjadi Rumah Moderasi Beragama.

Selain itu, perubahan status kelembagaan PTKIN ini didasari adanya regulasi yang berkembang di Indonesia, baik regulasi yang berupa Undang-Undang, Peraturan Pemerintah, Peraturan Menteri, maupun Keputusan Menteri. Sudah tentu terbitnya regulasi-regulasi tersebut di antaranya sebagai akibat dari tuntutan masyarakat dan perkembangan zaman (saat ini zaman/era industri 4.0 pada bonus demografi), khusunya perkembangan pendidikan tinggi di dunia. 
Rumus yang penulis gunakan dalam tulisan ini adalah Teori Kurt Lewin. Lewin (1951), yang mengungkapkan bahwa perubahan dapat dibedakan menjadi 3 (tiga) tahapan, yang meliputi:

\section{a. Unfreezing (pencairan)}

Proses perubahan ini harus memiliki motivasi yang kuat untuk berubah dari keadaan semula dengan merubah terhadap keseimbangan yang ada. Masalah biasanya muncul akibat adanya ketidakseimbangan dalam sistem. Tugas pimpinan PTKIN pada tahap ini adalah mengidentifikasi masalah dan memilih jalan keluar yang terbaik.

\section{b. Moving (bergerak)}

Proses perubahan tahap ini dapat terjadi apabila seseorang telah memiliki informasi yang cukup serta sikap dan kemampuan untuk berubah. Pada tahap ini pimpinan PTKIN berusaha mengumpulkan informasi dan mencari dukungan dari orang dan pihak lain yang dapat membantu memecahkan masalah.

\section{c. Refreezing (pembekuan)}

Tahap ini bisa disebut dengan tahap pembakuan, organisasi atau seseorang yang mengadakan perubahan telah mencapai tingkat atau tahapan yang baru dengan keseimbangan yang baru. Pada tahap ini pimpinan PTKIN sebagai agen berubahan berusaha mengatasi pihak-pihak atau orang-orang yang masih menghambat perubahan.

\section{Mendesign PTKIN di Era Industri 4.0,}

Jika tujuan kuliah untuk mendaptkan dan mengumpulkan ilmu pengetahuan, mahasiswa pada era digital tidak perlu duduk di bangku kuliah. Dengan fasilitas internet, mahasiswa dapat mencari informasi dan ilmu penegtahuan di manapun. Pembelajaran harus base on research yang diorientasikan pada penciptaan dan pengembangan ilmu pengetahuan. Mahasiswa harus dibekali lebih kuat logika keilmuan sebagai konsep dasar cara berfikir, baik logika 
deduktif maupun induktif atau cara berfikir yang menekankan pada prosedur pemecahan masalah. ${ }^{255}$

Orientasi pendidikan yang fokus pada kecerdasan kongnitif tidak akan mampu memenuhi kebutuhan esensial pendidikan. Pendidikan sudah sepatutnya mampu mengembangkan ilmu pengetahuan yang terpatri dalam perilaku positif. Wujud akhir dari pendidikan adalah membentuk karakter didik yang humanis. Nilai-nilai humanis adalah penjaga keharmonisan diri ditengah masyarakat. Dengan basis penelitian yang kuat dan terintegrasi, PTKIN harus memulai inovasi pengembangan ilmu dengan karakter khusus yakni pengembangan keilmuan dalam bidang science, dan sosial-keagamaan.

Sudah saatnya PTKIN mendesain masa depan melalui perangkat fundamental seperti meredesain rencana strategis, menyusun sistem penjaminan mutu PTKIN sehingga semuanya menjadi terencana, terstandar dan dapat terukur progress-nya. Kemudian tidak kalah pentingnya adalah setiap komponen harus melakukan pembacaan ulang terhadap tubuh dan muatan strategis masing-masing, bahkan jika diperlukan harus melakukan reformulasi paradigmatik dalam pengelolaan PTKIN.

PTKIN sebagai home intelectual level atas harus dikelola dengan penuh kesadaran tinggi dengan mengedepankan pembaharuan tekad dan sinergitas sivitas akademika untuk menata ulang orientasi PTKIN dengan cara berstrategi, bersikap, dan bertindak untuk kemajuan bersama. Mengelola PTKIN tidak semata tercapai dengan cara biasa akan tetapi membutuhkan lompatan kuantum dan sinergitas yang cukup signifikan. Lompatan secara rasional, kontekstual, berani dengan segala resiko, cermat serta cepat dalam memanfaatkan capaian-capaian pengembangan ilmu pengetahuan. Intinya, alih status adalah hijrah ilmiah yaitu suatu proses perubahan menuju PTKIN yang lebih baik. Semua progress ini membuat PTKIN lebih baik, terlebih dengan adanya era

255 http://pendis.kemenag.go.id/index.php?a=artikel\&id2=strategipendis diakses pada 02 September 2019 
industri 4.0 pada bonus demografi ini, semua harus berlandaskan pada Moderasi Bergama. Bahkan dengan adanya Surat Edaran Nomor B-3663.1/Dj.I/BA.02/10/2019 tertanggal 29 Oktober 2019 tentang Edaran Rumah Moderasi Beragama, maka seluruh PTKIN akan mendirikan dan memiliki Rumah Moderasi Beragama $^{256}$.

\section{KESIMPULAN}

Gempuran ideologi radikal yang menjadikan akses internet sebagai medianya, terkesan sangat revolusioner karena sebarannya sangat pesat, serta efek keterpengaruhannya pada generasi muda yang mempunyai semangat beragama. Pada saat ideologi yang sering tidak mengindahkan dialog dan konfirmasi ini menjadi trend baru, maka PTKIN (Perguruan Tinggi Keagamaan Islam Negeri) yang selama ini menjadikan moderasi sebagai sikap keberagamaannya, dimana Moderasi Beragama menjadi pengarus utamaan Kemenag RI, harus segera melakukan kampanye dan propagandanya di era Industri 4.0 pada bonus demografi ini.

Maka, harus ada mindsite yang "dipropagandakan" secara massif, yakni Islam merupakan agama yang membawa rahmah bagi seluruh makhluk, mengedepankan toleransi, ramah, terbuka untuk dialog dan tidak mengenal kekerasan serta ujaran kebencian dalam spirit dakwahnya. Ini menjadi bagian dalam memproduksi narasi Moderasi Bergama yang menjunjung tinggi nilai-nilai keberagaman-kebhenikaan, semangat kebangsaan di era Industri 4.0. ${ }^{257}$

Membenagun narasi Moderasi Beragama di tengah Industri 4.0 pada bonus demografi ini harus kita lakukan dengan cara massif, bagi penulis tindakan masif yang bisa dilakukan oleh sivitas akademika di bawah Kementerian Agama adalah melakukan Ahli Status PTKIN. Intinya, alih status adalah hijrah ilmiah yaitu suatu

256 https://kemenag.go.id/berita/read/511944/tiap-kampus-ptkinakan-dirikan-rumah-moderasi diakses pada 04 November 2019

257 Winarto Eka Wahyudi, "Cermin Bengis Media Sosial”, www.qureta. com/31-Januari-2018/ diakses pada 03 September 2019 
proses perubahan menuju PTKIN yang lebih baik. Semua progress ini membuat PTKIN lebih baik, terlebih dengan adanya era industri 4.0 pada bonus demografi ini, semua harus berlandaskan pada Moderasi Bergama. Bahkan dengan adanya Surat Edaran Nomor B-3663.1/Dj.I/BA.02/10/2019 tertanggal 29 Oktober 2019 tentang Edaran Rumah Moderasi Beragama, maka seluruh PTKIN akan mendirikan dan memiliki Rumah Moderasi Beragama $^{258}$.

Proses ahli status STAIN ke IAIN, atau IAIN ke UIN ini tentu akan mememperkuat eksistensi keberadaan perguruanperguruan tinggi di bawah Kementerian Agama. Perguruan Tinggi yang menjadi tempat produksi pengetahuan dan dapat melahirkan cendikiawan-cendikiawan hebat ini akan semakin dapat menarasikan Moderasi Beragama menjadi lebih besar lagi saat perguruan tinggi tersebut semakin besar (salah satu indikasi besar tersebut adalah perubahan ahli status, dari STAIN ke IAIN, atau dari IAIN ke UIN).

\section{HARAPAN}

Buku RUMAH MODERASI BERAGAMA: PERSPEKTIF LINTAS KEILMUAN (Karya Tulis CPNS 2018 IAIN Sultan Amai Gorontalo sebagai Dukungan Terhadap Alih Status Menjadi UIN Sultan Amai Gorontalo) terdiri dari 16 tulisan yang ditulis oleh 16 penulis muda, saat kumpulan tulisan ini terbit sebagai sebuah buku, kami berstatus CPNS di Satuan Kerja IAIN Sultan Amai Gorontalo yang baru saja melaksanakan Latsar (Pelatihan Dasar, dahulu disebut Prajab) On Campus 1 di Balai Diklat Keagamaan Manado Gol. III, Gelombang III.

16 penulis ini adalah Abdur Rahman Adi Saputra, Aminudin, Andiani Rezkita Nabu, Arfan Nusi, Basri, Dian Adi Perdana, Dikson T. Yasin, Djunawir Syafar, Eka Apristian Pantu, Firman Sidik, Habibie Yusuf, M. Rifian Panigoro, Rifadli D. Kadir, Sitti Rahmawati Talango, Sri Aprianty Husain, Suheil.

258 https://kemenag.go.id/berita/read/511944/tiap-kampus-ptkin-akan-

dirikan-rumah-moderasi diakses pada 04 November 2019 
Editor dalam buku ini adalah Dr. Ahmad Faisal, M.Ag. (Wakil Rektor 2 IAIN Sultan Amai Gorontalo), Khaeroni. M.Si. (Kepala Balai Diklat Keagamaan Manado), Habibie Yusuf, S.Pd.I, M.Pd. (Sivitas Akademika IAIN Sultan Amai Gorontalo). Kolaborasi berbagai unsur editor mencerminkan proses terbitnya buku ini pun sudah sangat Moderasi Beragama, dan seluruh penulis selalu siap bekerjasama dengan siapapun untuk membangun Bangsa.

Buku ini pun diberi endorsement oleh: Dr. Mahrus, M.Ag (Kepala Seksi Penelitian dan Pengelolaan Hak Kekayaan Intelektual Kemenag RI), Dr. Ahmad Faisal, M.Ag (Wakil Rektor 2 IAIN Sultan Amai Gorontalo), Dr. Kasim Yahiji, M.Ag (Direktur Pascasarjana IAIN Sultan Amai Gorontalo), Dr. Lukman Arsyad, M.Pd (Dekan Fakultas Ilmu Tarbiyah dan Keguruan IAIN Sultan Amai Gorontalo), Dr. H. Ayub Ishak, M.A (Dekan Fakultas Syariah dan Dakwah IAIN Sultan Amai Gorontalo), Dr. Mashadi, M.Si (Dekan Fakultas Ushuluddin dan Dakwah IAIN Sultan Amai Gorontalo), Dr. Muhibbuddin, M.Si (Dekan Fakultas Ekonomi dan Bisnis Islam IAIN Sultan Amai Gorontalo).

Kata pengantar buku ini oleh Prof. Dr. Oman Fathurrahman, M.Hum (Staf Ahli Menteri Agama RI Bidang Manajemen Komunikasi dan Informasi). Kata sambutan buku ini oleh DR. Lahaji Haedar, M.Ag (Rektor IAIN Sultan Amai Gorontalo).

Harapan yang sangat besar, buku ini dapat bermanfaat bagi banyak orang, membawa keberkahan untuk semua yang terlibat dan berkontribusi pada karya buku ini. Serta buku ini selalu menjadi semangat bagi kita semua agar terus berkarya untuk Bangsa. 


\section{REFERENSI}

Azra "Pendidikan Tinggi Islam dan Kemajuan Sains (Sebuah Pengantar)", dalam Charles Michael Stanton, Pendidikan Tinggi dalam Islam, Terj. H. Afandi dan Hasan Asari, Jakarta: Logos, 1994.

---------, "Studi-studi Agama di Perguruan Tinggi Agama Islam Negeri," dalam Pendidikan Islam, Jakarta: Logos, 1999.

, Jaringan Intelektual Ulama Nusantara, Bandung: Mizan, 1994.

Bogdan dan Biklen, Qualitative Research For Education : An Introduction to Theory and Method, Boston: Allyn and Bacon, Inc, 1993.

Castetter, William. B. (1996). The Human Research for Educational Administration.

DEPAG RI., 2000. Buklet Direktorat Pembinaan Perguruan Tinggi Agama, Jakarta: Departemen Agama RI.

Direktorat Jenderal Pendidikan Islam Depag. RI, 2006. Undangundang dan Peraturan Pemerintah RI. Tentang Pendidikan, Jakarta: Direkt. Jend. Pend. Islam Depag. RI.

Hidayat, Komaruddin dan Hendro Prasetiyo (ed.), 2000. "Menilik Dinamika IAIN", dalam Problem dan Prospek IAIN: Antologi Pendidikan Tinggi Islam, Ditpertais Depag. RI.

Hilmy, Masdar "Whither Indonesia's Islamic Moderatism? A Reexamination on the Moderate Vision of Muhammadiyah and NU," Journal of Indonesian Islam 7, no. 1 (Juni 2013): 25.

Kasali, Rhenald. 2017. Disruption: Tak Ada yang Tak Bisa Diubah Sebelum Dihadapi, Motivasi Saja Tidak Cukup, Jakarta: Gramedia Pustaka Utama. 
Made Pidarta, 2008. Manajemen Pendidikan Indonesia. Jakarta: Bina Aksara.

PMA Pasal 215 tahun 2014

Tebba, Sudirman, 1993. "Orientasi Mahasiswa dan Kajian Islam IAIN," dalam Islam Orde Baru, Yogyakarta: Tiara Wacana.

Tibi, Bassam, 1991. Islam and the Cultural Accommodation of Social Change, Boulder.

Wahid, Abdurrahman.. 2006. Islamku Islam Anda Islam Kita: Agama Masyarakat Negara Demokrasi, Jakarta: The Wahid Institute.

Yusuf, Habibie. 2019 "Pokoknya Administrasi Pendidikan" Tulungagung; CV. Cahaya Abadi. 